\section{Association of IFI200 Gene Polymorphisms with Susceptibility to Systemic Lupus Erythematosus}

\section{To the Editor:}

The MNDA (myeloid nuclear differentiation antigen), IFIX (interferon-inducible protein X), IFII6 (interferon-inducible protein 16), and AIM2 (absent in melanoma 2) are a group of interferon (IFN)-inducible genes whose products belong to the gene family denoted hematopoietic interferon-inducible protein with 200 amino acid repeat (IFI200). These genes map on chromosome 1q21-23, which is the major susceptibility locus of systemic lupus erythematosus (SLE). They are proposed as new candidate genes for SLE susceptibility for several reasons: (1) genetic mapping from a murine model of lupus ${ }^{1,2}$; (2) upregulation of all 4 genes in patients with $\mathrm{SLE}^{3}$; (3) the role of IFI16 as autoantigen in patients with $\mathrm{SLE}^{4,5}$; (4) the ability of IFI16 to bind single-strand DNA in a process of DNA repair ${ }^{6}$; and (5) the discovery of AIM2 as an intracellular DNA sensor leading to inflammation and apoptosis ${ }^{7}$. Therefore, IFI200 might be associated with abnormal inflammation and loss of tolerance to dsDNA observed in patients with SLE.

We recruited 200 SLE patients (194 women, 6 men; mean age $36.21 \pm$ SD 10.76 yrs) from King Chulalongkorn Memorial Hospital, Bangkok, each having at least 4 of the American College of Rheumatology revised criteria for $\mathrm{SLE}^{8}$, and 200 ethnically matched healthy volunteer blood donors from the Thai Red Cross Society (147 women, 53 men; mean age $23 \pm \mathrm{SD} 12.3 \mathrm{yrs})^{9}$. The study was approved by the ethics committee of the Faculty of Medicine, Chulalongkorn University, and all subjects gave their informed consent.

Detection of apoptosis. Within 60 minutes after blood draw, peripheral blood mononuclear cells (PBMC) from 15 healthy donors containing different IFI16 genotypes were isolated by Ficoll-Hypaque gradient (Robbins Scientific, Sunnyvale, CA, USA) and resuspended in RPMI-1640 medium (Sigma, New York, NY, USA) with $10 \%$ fetal bovine serum (Gibco,
Karlsruhe, Germany) and $100 \mathrm{U} / \mathrm{ml}$ penicillin (Gibco) and $100 \mu \mathrm{g} / \mathrm{ml}$ streptomycin (Gibco) at concentration $5 \times 10^{6} \mathrm{cells} / \mathrm{ml}$. These cells were plated into 24-well plastic tissue culture plates. PBMC were treated with doxorubicin (Pharmacia and Upjohn GmbH, Freiburg, Germany) at a concentration of $10 \mu \mathrm{g} / \mathrm{ml}$ and then cultured at $37^{\circ} \mathrm{C}$ in $5 \% \mathrm{CO}_{2}$ for $24 \mathrm{~h}$. This condition was determined to be effective to induce highest $\mathrm{p} 53$ expression in dose $(1,10$, and $100 \mu \mathrm{g} / \mathrm{ml})$ and time $(8$ and $24 \mathrm{~h})$ response experiments. p53 mRNA expression was studied using real-time reverse transcription-polymerase chain reaction (RT-PCR) with the following primers: 5'TGG CCA TCT ACA AGC AGT CAC A3' and 5'GCA AAT TTC CTT CCA CTC GGA T3', as described ${ }^{10}$. Finally, the percentage of apoptotic cells was measured by FACScan flow cytometry (Becton Dickinson, Mountain View, CA, USA) for annexin V-FITC and propidium iodide binding according to the manufacturer's protocol (BD Biosciences Pharmingen, San Diego, CA, USA). Cells positive only for annexin V were counted as apoptotic.

Quantification of IFIX and IFII6 isoforms. Expression of IFIX and IFII6 isoforms was semiquantified by conventional RT-PCR using the following primers: 5'GGA ACA GAG TCA GCA TCC and 5'GTT ATT TGA TAT CCT TGT CC for IFIX ${ }^{11}$; and 5'CAT CTT CGG ACT CCT CAG and 5'GTT CAG CAC CAT CAC TTC for IFI16. cDNA from leukocytes of 19 SLE patients containing different genotypes was amplified in a Perkin Elmer/GeneAmp PCR 2400 system. The PCR conditions consisted of initial denaturation at $94^{\circ} \mathrm{C}$ for $5 \mathrm{~min}$, followed by 30 cycles of denaturation $\left(94^{\circ} \mathrm{C}, 30 \mathrm{~s}\right)$, annealing $\left(60^{\circ} \mathrm{C}\right.$ for $I F I X$ gene, $62^{\circ} \mathrm{C}$ for $I F I 16$ gene, $\left.30 \mathrm{~s}\right)$, extension $\left(72^{\circ} \mathrm{C}, 30 \mathrm{~s}\right)$, and final extension $\left(72^{\circ} \mathrm{C}, 7 \mathrm{~min}\right)$. PCR products were loaded in $1.5 \%$ Tris-acetate agarose gel and analyzed by electrophoresis in Tris-acetate buffer at 100 volts for 40 min followed by staining with $50 \mu \mathrm{g} / \mathrm{ml}$ ethidium bromide. The density of product bands was semiquantified using Gel Doc ${ }^{\mathrm{TM}}$ MZL software (Bio-Rad).

Statistical analysis. The association between genotypes and the expression of isoforms or apoptosis was analyzed by GraphPad Prism, version 4.0

Table 1. Putative functional single-nucleotide polymorphisms (SNP) and genotyping methods.

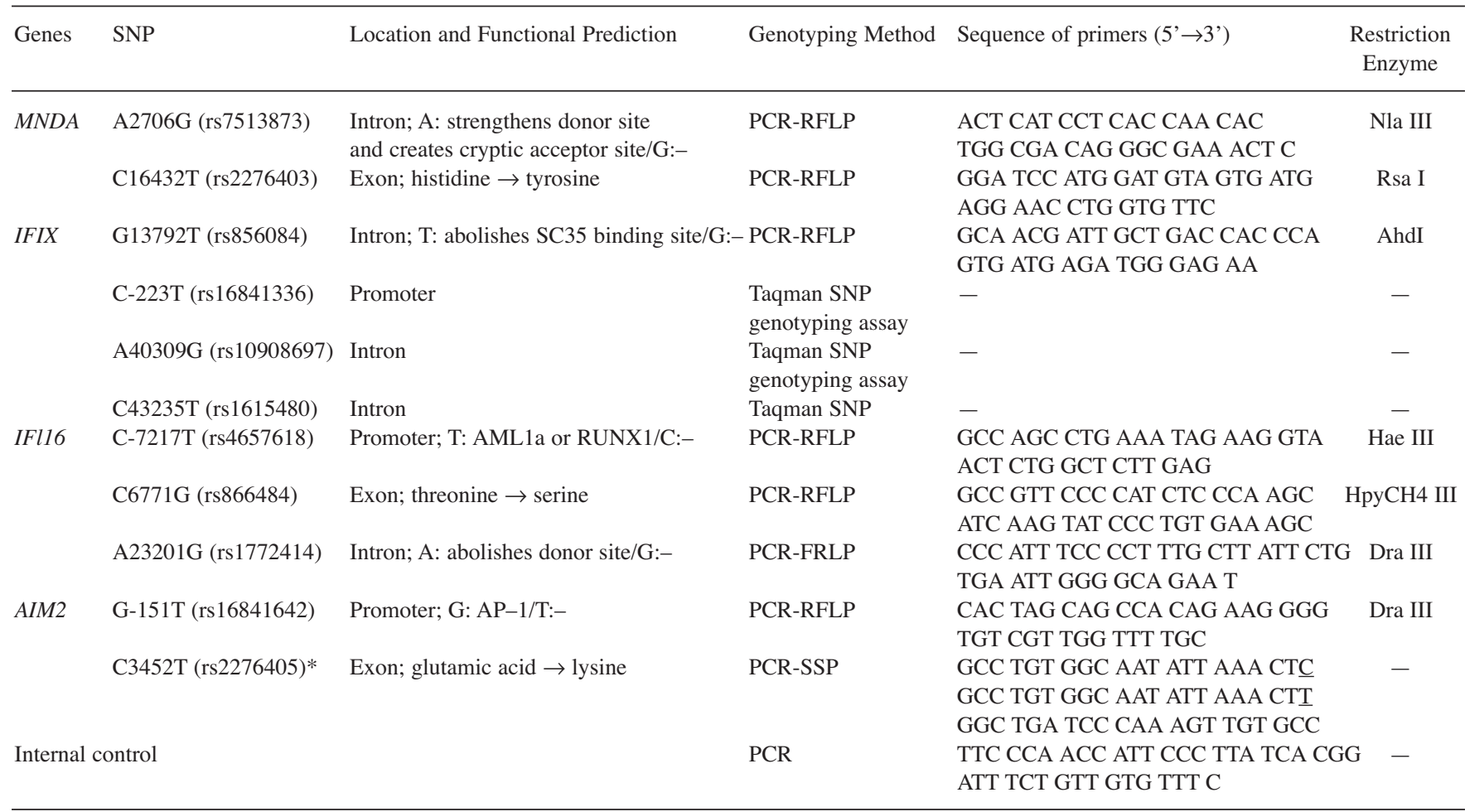

\footnotetext{
* Not polymorphic in the Thai population. PCR-FRLP: polymerase chain reaction-restriction fragment length polymorphism; PCR-SSP: polymerase chain
} reaction-sequence specific primer. 
(Graph-Pad Software, San Diego, CA, USA). The Mann-Whitney U test was used in comparisons between 2 groups, while Kruskal-Walls $\mathrm{H}$ was applied in case of analysis of more than 2 groups. A p value $<0.05$ was considered significant.

Eleven putative functional single-nucleotide polymorphisms (SNP) were selected from MNDA, IFIX, IFI16, and AIM2 genes according to computational prediction and genotyped as described in Table 1 . The percentage of genotyping for each SNP was $100 \%$. There were no missing genotyping data. All SNP were in Hardy-Weinberg equilibrium when we compared the observed with the expected genotype frequencies of each SNP $(p>0.05)$. PLINK v1.05 program ${ }^{12}$ was used to calculate $p$ values, empirical $p$ values $(100,000$ permutations), and odds ratios $(95 \%$ confidence intervals) for genotype and haplotype associations. Linkage disequilibrium was determined by JLIN, a Java-based linkage disequilibrium plot$\operatorname{ter}^{13}$ (Table 2).

A significant association of the minor allele frequency from $3 \mathrm{SNP}$ of IFIX and IFII6 genes was found between SLE patients and healthy controls (Table 3). The G13792T (rs856084) in IFIX and the C6771G (rs866484) and A23201G (rs1772414) in IFI16 showed significant differences (OR 0.73, 95\% CI 0.54-0.98, empirical $\mathrm{p}=0.033$; OR $1.33,95 \% \mathrm{CI}$ $1.00-1.75$, empirical $\mathrm{p}=0.05$; and OR $1.37,95 \%$ CI $1.03-1.80$, empirical $\mathrm{p}=0.030$, respectively). The association of both SNP (rs866484 and rs 1772414) in IFI16 gene seems to be a recessive effect model. The presence of $2 \mathrm{G}$ alleles $(\mathrm{GG})$ conferred a significant $\mathrm{p}=0.009$ (empirical $\mathrm{p}=$ 0.023 ) for $\mathrm{rs} 866484$ and $\mathrm{p}=0.013$ (empirical $\mathrm{p}=0.032$ ) for $\mathrm{rs} 1772414$. The marginal significance results are probably due to the limited sample size in this study. We performed haplotype analysis of significant SNP rs866484 and rs1772414 with the strongest linkage disequilibrium ( $\mathrm{D}^{\prime}=$ 0.814 and $r^{2}=0.643$ ) by comparing each haplotype with another 3 haplotypes between SLE patients and controls. Our finding showed that the GG was a risk haplotype (OR 1.41 and $p=0.017$, empirical $p=0.031$ ), whereas $\mathrm{CA}$ was a protective haplotype (OR 0.73 and $\mathrm{p}=0.032$, empirical $\mathrm{p}=$ $0.041)$.

Regarding the selection as putative functional SNP, we tried to prove our hypothesis of 3 positive SNP as follows. SNP rs866484 (C6771G) of IFI16 is a nonsynonymous SNP whose amino acid is altered from threonine to serine. This SNP is located on an A-type repeat containing p53 binding site. Binding of IFI16 protein to the C-terminus of $\mathrm{p} 53$ has been reported to stimulate the transcription of p53-responsive reporter plasmids and leads to susceptibility to apoptosis of cells ${ }^{14}$. We hypothesized that the $\mathrm{G}$ risk allele may bind $\mathrm{p} 53$ with higher affinity and lead to more apoptosis. We conducted our experiment by inducing the highest p53 mRNA expression with doxorubicin at a concentration of $10 \mu \mathrm{g} / \mathrm{ml}$ for $24 \mathrm{~h}$. The association of SNP rs866484 and apoptosis rate was studied by flow cytometry analysis. We were unable to determine the association between SNP and apoptosis (Figure 1A). This negative finding may be because threonine and serine are in the same amino acid group. Nevertheless, further study should be performed using direct protein-protein interaction methods to prove the direct role of this SNP in protein structure that affects $\mathrm{p} 53$ binding. In addition, we tested the association of the $2 \mathrm{SNP}$ within the intron of IFIX (rs856084) and IFI16 (rs1772414) genes with the expression of the isoforms ( $\alpha$ and $B$ for IFIX; A, B, and C for IFI16) by reverse transcriptionpolymerase chain reaction, as described ${ }^{3}$. However, we found no differences in isoforms among the genotypes (Figure 1B, 1C, 1D).

Our results suggest that these SNP are not likely to be functional SNP. We could not exclude the possibility that these SNP are in linkage disequilibrium with nearby causative SNP. Interestingly, one report in SLE in Caucasian patients also suggested an association signal in the IFIX-IFI16 intergenic region ${ }^{15}$. More extensive research using dense SNP and increased sample sizes is required to clarify the role of IFIX and IFII6 gene in SLE.

INGORN KIMKONG, Medical Microbiology Interdisciplinary Program, Graduate School, Chulalongkorn University, Bangkok; YINGYOS AVIHINGSANON, Lupus Research Unit, Department of Medicine, Faculty of Medicine, Chulalongkorn University, Bangkok; NATTIYA HIRANKARN, MD, PhD, Lupus Research Unit, Department of Microbiology, Faculty of Medicine, Chulalongkorn University, Rama 4 Road, Bangkok 10330, Thailand. Address correspondence to Dr. Hirankarn; E-mail: fmednpt@md.chula.ac.th

Supported in part by a research grant from the Lupus Research Unit, the 90th Year Anniversary of Chulalongkorn University

(Ratchadaphiseksomphot Endownment Fund) and the National Research Council of Thailand 2008-2009.

Table 2. Linkage disequilibrium coefficients (D' and $\mathrm{r}^{2}$ ) among single-nucleotide polymorphisms (SNP) within MNDA, IFIX, IFI16, and AIM2.

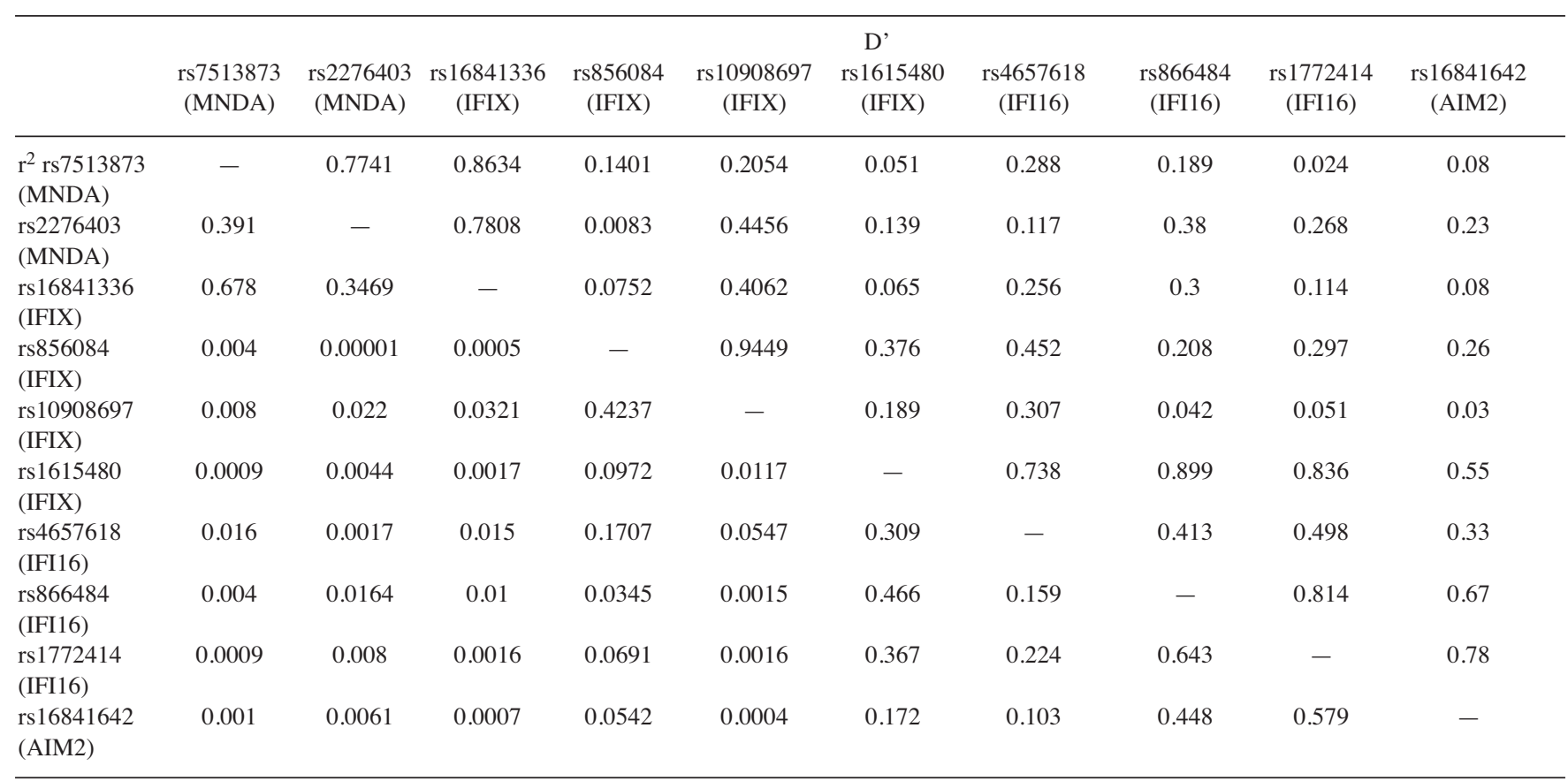


Table 3. Genotype and allele frequencies for MNDA, IFIX, IFI16, and AIM2 polymorphisms in SLE patients and healthy controls. Significant results (p value $<0.05$ ) indicated in bold type.

\begin{tabular}{|c|c|c|c|c|c|c|c|c|c|c|c|c|c|c|c|c|c|}
\hline \multirow{3}{*}{ Gene } & \multirow{3}{*}{ SNP } & \multirow{3}{*}{$\begin{array}{c}\text { Minor } \\
\text { a }\end{array}$} & \multirow{3}{*}{$\begin{array}{c}\text { Major } \\
\text { A }\end{array}$} & \multicolumn{5}{|c|}{ SLE, $n=200$} & \multicolumn{5}{|c|}{ Control, $\mathrm{n}=200$} & \multirow{2}{*}{\multicolumn{2}{|c|}{$\begin{array}{l}\text { Model of Inheritance } \\
\text { (Recessive) }\end{array}$}} & \multirow{2}{*}{\multicolumn{2}{|c|}{ Allelic Test* }} \\
\hline & & & & \multicolumn{3}{|c|}{ Genotype, n (\%) } & \multicolumn{2}{|c|}{ Allele, n (\%) } & \multicolumn{3}{|c|}{ Genotype, $\mathrm{n}(\%)$} & \multicolumn{2}{|c|}{ Allele, $\mathrm{n}(\%)$} & & & & \\
\hline & & & & aa & $\mathrm{Aa}$ & AA & a & A & aa & $\mathrm{Aa}$ & AA & $\mathrm{a}$ & A & OR $(95 \% \mathrm{CI})$ & Emp p & OR $(95 \% \mathrm{CI})$ & Emp p \\
\hline \multirow[t]{2}{*}{$M N D A$} & rs7513873 & A & G & $1(0.5)$ & $50(25)$ & $149(75)$ & $52(13)$ & $348(87)$ & $1(0.5)$ & $45(22.5)$ & $154(77)$ & $47(11.8)$ & $353(88.3)$ & NA & NA & $1.12(0.74-1.71)$ & 0.571 \\
\hline & rs 2276403 & $\mathrm{~T}$ & $\mathrm{C}$ & $1(0.5)$ & $37(19)$ & $162(81)$ & $39(9.75)$ & $361(90.25)$ & $0(0)$ & $32(16)$ & $168(84)$ & $32(8)$ & $368(92)$ & $\mathrm{NA}$ & $\mathrm{NA}$ & $1.24(0.76-2.03)$ & 0.372 \\
\hline \multirow[t]{2}{*}{ IFIX } & rs16841336 & $6 \mathrm{C}$ & $\mathrm{T}$ & $4(2)$ & $53(27)$ & $143(72)$ & $61(15.3)$ & $339(84.75)$ & $3(1.5)$ & $55(27.5)$ & $142(71)$ & $61(15.3)$ & $339(84.8)$ & NA & NA & $1(0.68-1.47)$ & 1 \\
\hline & rs856084 & G & $\mathrm{T}$ & $15(7.5)$ & $88(44)$ & $97(49)$ & $118(29.5)$ & $282(70.5)$ & 27 (14) & $92(46)$ & $81(40.5)$ & $146(36.5)$ & $254(63.5)$ & $0.52(0.25-1.06)$ & 0.079 & $0.73(0.54-0.98)$ & 0.033 \\
\hline \multirow[t]{3}{*}{ IFI16 } & rs4657618 & $\mathrm{T}$ & $\mathrm{C}$ & $32(16) 1$ & $101(51)$ & $67(34)$ & $165(41.3)$ & $235(58.75)$ & $34(17)$ & $98(49)$ & $68(34)$ & $166(41.5)$ & $234(58.5)$ & $0.93(0.53-1.63)$ & 0.956 & $0.99(0.75-1.31)$ & 0.946 \\
\hline & rs866484 & G & $\mathrm{C}$ & $57(29)$ & 87 (44) & $56(28)$ & $201(50.3)$ & $199(49.75)$ & $35(18)$ & $103(51.5)$ & $62(31)$ & $173(43.3)$ & $227(56.8)$ & $1.88(1.14-3.11)^{\dagger}$ & 0.023 & $1.33(1.00-1.75)$ & 0.050 \\
\hline & rs 1772414 & G & A & $57(29)$ & $93(47)$ & $50(25)$ & $207(51.8)$ & $193(48.25)$ & $36(18)$ & $104(52)$ & $60(30)$ & $176(44)$ & $224(56)$ & $1.82(1.10-3.00)^{\dagger \dagger}$ & 0.032 & $1.37(1.03-1.80)$ & 0.030 \\
\hline \multirow[t]{2}{*}{ AIM2 } & rs16841642 & $\mathrm{T}$ & G & $41(21)$ & $94(47)$ & $65(33)$ & $176(44)$ & $224(56)$ & $35(18)$ & $102(51)$ & $63(31.5)$ & $172(43)$ & $228(57)$ & $1.22(0.72-2.07)$ & 0.694 & $1.04(0.79-1.38)$ & 0.779 \\
\hline & rs2276405 & $\mathrm{C}$ & T 2 & $200(100)$ & $0(0)$ & $0(0)$ & $400(100)$ & $0(0)$ & $200(100)$ & $0(0)$ & $0(0)$ & $400(100)$ & $0(0)$ & NA & NA & NA & NA \\
\hline
\end{tabular}

$*$ SNP were analyzed for association with disease by comparison of minor allele frequency in SLE patients and controls. ${ }^{\dagger} \mathrm{GG}$ compared with CG+CC genotypes. ${ }^{\dagger \dagger} \mathrm{GG}$ compared with AG+AA genotypes. NA: not applicable; SNP: single-nucleotide polymorphism; EMP p: empirical p value (100,000 permutations).
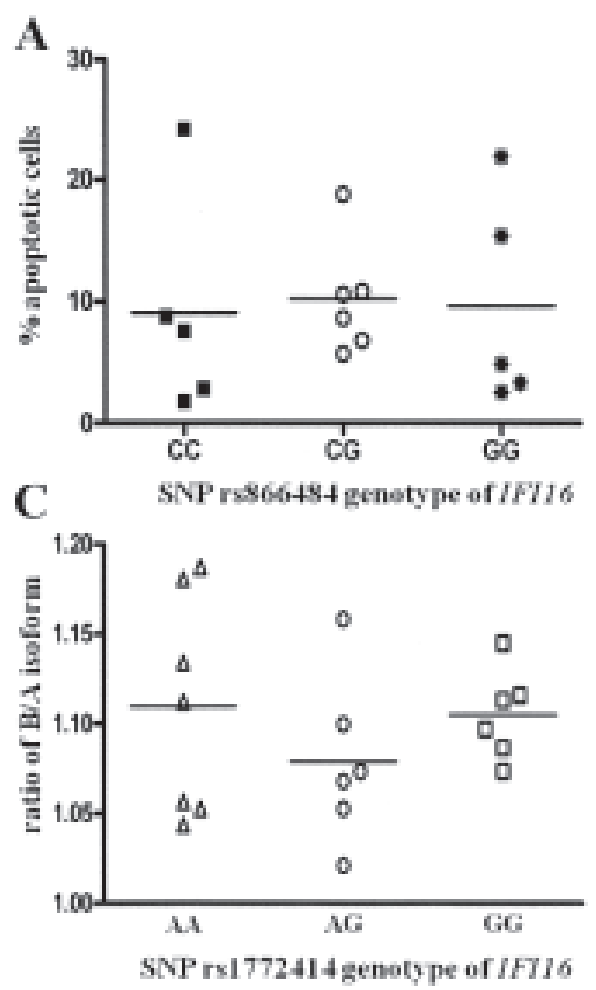

B

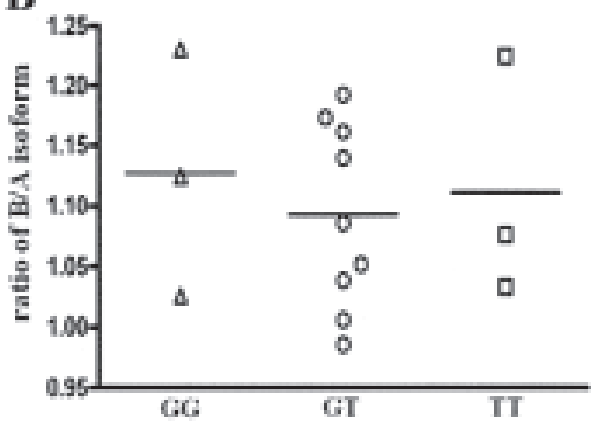

D SNP rs 86084 genotype of $I F 7 \mathrm{~N}$

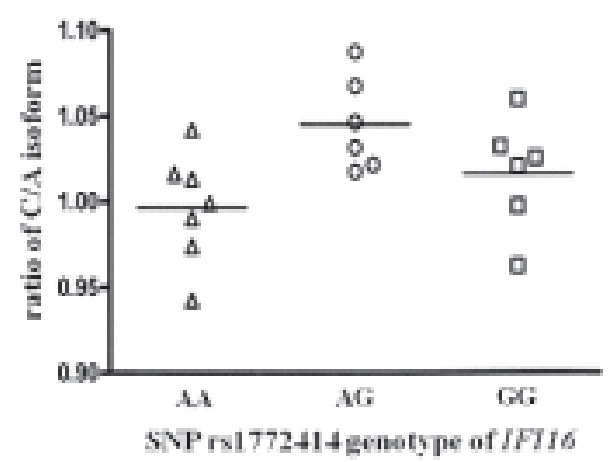

Figure 1. A. The effect of SNP rs866484 genotypes (CC, CG, and GG; $\mathrm{n}=5,6$, and 5, respectively) on apoptotic response of healthy PBMC treated with $10 \mu \mathrm{g} / \mathrm{ml}$ doxorubicin for $24 \mathrm{~h}$. B, C, D. The ratio of short product/full-length product grouped by SNP rs856084 genotypes of IFIX (GG, GT, and TT; n = 3, 9, and 3) and SNP rs 1772414 genotypes of IFI16 (AA, AG, and GG; n = 7, 6, and 6). Each data symbol represents an individual sample; horizontal lines show median values.

\section{REFERENCES}

1. Rozzo SJ, Allard JD, Choubey D, Vyse TJ, Izui S, Peltz G, et al. Evidence for an interferon-inducible gene, Ifi202, in the susceptibility to systemic lupus. Immunity 2001;15:435-43.

2. Choubey D, Panchanathan R. Interferon-inducible Ifi200-family genes in systemic lupus erythematosus. Immunol Lett 2008;119:32-41.
3. Kimkong I, Avihingsanon Y, Hirankarn N. Expression profile of HIN200 in leukocytes and renal biopsy of SLE patients by real-time RT-PCR. Lupus 2009;18:1066-72.

4. Seelig HP, Ehrfeld H, Renz M. Interferon-gamma-inducible protein p16. A new target of antinuclear antibodies in patients with systemic lupus erythematosus. Arthritis Rheum 1994;37:1672-83.

5. Mondini M, Vidali M, Airo P, De Andrea M, Riboldi P, Meroni PL, 
et al. Role of the interferon-inducible gene IFI16 in the etiopathogenesis of systemic autoimmune disorders. Ann NY Acad Sci 2007;1110:47-56.

6. Yan H, Dalal K, Hon BK, Youkharibache P, Lau D, Pio F. RPA nucleic acid-binding properties of IFI16-HIN200. Biochim Biophys Acta 2008;1784:1087-97.

7. Fernandes-Alnemri T, Yu JW, Datta P, Wu J, Alnemri ES. AIM2 activates the inflammasome and cell death in response to cytoplasmic DNA. Nature 2009;458:509-13.

8. Tan EM, Cohen AS, Fries JF, Masi AT, McShane DJ, Rothfield NF, et al. The 1982 American College of Rheumatology revised criteria for the classification of systemic lupus erythematosus. Arthritis Rheum 1982;25:1271-7.

9. Hirankarn N, Avihingsanon Y, Wongpiyabovorn J. Genetic susceptibility to SLE is associated with TNF-alpha gene polymorphism -863 , but not -308 and -238 , in Thai population. Int J Immunogenet 2007;34:425-30.
10. Yu L, Domann FE. Rapid and direct quantitative RT-PCR method to measure promoter activity. Biotechnol Prog 2006;22:1461-3.

11. Ding, et al. 2004.

12. Purcell S, Neale B, Todd-Brown K, Thomas L, Ferreira MA, Bender D, Maller J, et al. PLINK: a tool set for whole-genome association and population-based linkage analyses. Am J Hum Genet 2007;81:559-75.

13. Carter KW, McCaskie PA, Palmer LJ. JLIN: a Java based linkage disequilibrium plotter. BMC Bioinformatics 2006;7:60.

14. Johnstone RW, Wei W, Greenway A, Trapani JA. Functional interaction between $\mathrm{p} 53$ and the interferon-inducible nucleoprotein IFI 16. Oncogene 2000;19:6033-42.

15. Fernando MM, Rigby RJ, Roberton CA, Rioux JD, Vyse TJ. Interferon-inducibile genes on chromosome 1 contribute to lupus susceptibility. Rheumatology 2006;45:i15-i16.

J Rheumatol 2010;37:7; doi:10.3899/jrheum.091255 